\title{
Peripheral blood bovine lymphocytes and MAP show distinctly different proteome changes and immune pathways in host- pathogen interaction
}

\author{
Kristina JH Kleinwort ${ }^{1}$, Stefanie M Hauck ${ }^{2}$, Roxane L Degroote ${ }^{1}$, Armin M Scholz ${ }^{3}$, Christina Hoelzel $^{4,5}$, Erwin P \\ Maertlbauer $^{5}$, Cornelia Deeg ${ }^{\text {Corresp. } 1}$ \\ ${ }^{1}$ Chair of Animal Physiology, Department of Veterinary Sciences, LMU Munich, Munich, Germany \\ 2 Research Unit for Protein Science, Helmholtz Zentrum Munich, German Research Center for Environmental Health GmbH, Munich, Germany \\ 3 Livestock Center of the Faculty of Veterinary Medicine, LMU Munich, Oberschleissheim, Germany \\ 4 Institute of Animal Breeding and Husbandry, Faculty of Agricultural and Nutritional Sciences, CAU Kiel, Kiel, Germany \\ ${ }^{5}$ Chair of Hygiene and Technology of Milk, Department of Veterinary Sciences, LMU Munich, Oberschleissheim, Germany \\ Corresponding Author: Cornelia Deeg \\ Email address: Cornelia.Deeg@Imu.de
}

Mycobacterium avium subsp. paratuberculosis (MAP) is a pathogen causing paratuberculosis in cattle and small ruminants. During the long asymptomatic subclinical stage, high numbers of MAP are excreted and can be transmitted to food for human consumption, where they survive many of the standard techniques of food decontamination. Whether MAP is a human pathogen is currently under debate. The aim of this study was a better understanding of the host-pathogen response by analysing the interaction of peripheral blood lymphocytes (PBL) from cattle with MAP in their exoproteomes/secretomes to gain more information about the pathogenic mechanisms of MAP. Because in other mycobacterial infections, the immune phenotype correlates with susceptibility, we additionally tested the interaction of MAP with recently detected cattle with a different immune capacity referred as immune deviant (ID) cows. In PBL, different biological pathways were enhanced in response to MAP dependent on the immune phenotype of the host. PBL of control cows activated members of cell activation and chemotaxis of leukocytes pathway as well as IL-12 mediated signaling. In contrast, in ID cows CNOT1 was detected as highly abundant protein, pointing to a different immune response, which could be favorable for MAP. Additionally, MAP exoproteomes differed in either GroEL1 or DnaK abundance, depending on the interacting host immune response. These finding point to an interdependent, tightly regulated response of the bovine immune system to MAP and vice versa. 


\section{$1 \quad$ Peripheral blood bovine lymphocytes and MAP show distinctly}

2 different proteome changes and immune pathways in host-pathogen

\section{interaction}

Kristina J.H. Kleinwort ${ }^{1}$, Stefanie M. Hauck ${ }^{2}$, Roxane L. Degroote ${ }^{1}$, Armin M. Scholz ${ }^{3}$,

81 Chair of Animal Physiology, Department of Veterinary Sciences, LMU Munich, Veterinärstraße

9 13, D-80539 Munich, Germany;

102 Research Unit for Protein Science, Helmholtz Zentrum Munich, German Research Center for

11 Environmental Health GmbH, Munich, Germany;

123 Livestock Center of the Faculty of Veterinary Medicine, LMU Munich, Oberschleissheim, 13 Germany;

144 Chair of Hygiene and Technology of Milk, Department of Veterinary Sciences, LMU Munich, 15 Schönleutnerstr 8, D-85764 Oberschleissheim, Germany;

165 Institute of Animal Breeding and Husbandry, Faculty of Agricultural and Nutritional Sciences, 17 CAU Kiel, Hermann-Rodewald-Str. 6, 24098 Kiel, Germany;

* Corresponding author: Cornelia A. Deeg, Chair for Animal Physiology, Department of

20 Veterinary Sciences, LMU Munich, Veterinärstr. 13, D-80539 Munich. E-mail:

21 Cornelia.Deeg@lmu.de, Phone: +49-89-2180-2551; Fax: +49-89-2180-2554.

Abstract: Mycobacterium avium subsp. paratuberculosis (MAP) is a pathogen causing paratuberculosis in cattle and small ruminants. During the long asymptomatic subclinical stage, 
25 high numbers of MAP are excreted and can be transmitted to food for human consumption, where

26 they survive many of the standard techniques of food decontamination. Whether MAP is a human

27 pathogen is currently under debate.

28 The aim of this study was a better understanding of the host-pathogen response by analysing the

29 interaction of peripheral blood lymphocytes (PBL) from cattle with MAP in their

30 exoproteomes/secretomes to gain more information about the pathogenic mechanisms of MAP.

31 Because in other mycobacterial infections, the immune phenotype correlates with susceptibility,

32 we additionally tested the interaction of MAP with recently detected cattle with a different immune

33 capacity referred as immune deviant (ID) cows.

34 In PBL, different biological pathways were enhanced in response to MAP dependent on the

35 immune phenotype of the host. PBL of control cows activated members of cell activation and

36 chemotaxis of leukocytes pathway as well as IL-12 mediated signaling. In contrast, in ID cows

37 CNOT1 was detected as highly abundant protein, pointing to a different immune response, which

38 could be favorable for MAP. Additionally, MAP exoproteomes differed in either GroEL1 or

39 DnaK abundance, depending on the interacting host immune response.

40 These finding point to an interdependent, tightly regulated response of the bovine immune 41 system to MAP and vice versa.

42 Keywords: Mycobacterium avium subsp. paratuberculosis, exoproteome, immune capacity, IL43 12, CNOT, GroEL1, DnaK, ShinyGO

\section{Introduction}


47 small ruminants, causing paratuberculosis with decreased milk production and, in some animals, excessive loss of weight (Yamamoto et al. 2018). Paratuberculosis, also referred to as Johne's disease, is endemic world-wide endemic; no country or region has been found to be free of this disease ( $\mathrm{Li}$ et al. 2016). Affected ruminants go through a long asymptomatic subclinical phase in which infection cannot reliably be detected by standard diagnostic tests (Hobmaier et al. 2019; Li et al. 2017). These subclinically infected animals can already shed or harbour MAP and thereby contaminate dairy products or meat (Sweeney 2011). Diseased animals were shown to shed high numbers of MAP (Machado et al. 2018). Since viable MAP were found in pasteurized milk (Gerrard et al. 2018), dried dairy products like powdered infant formula (Botsaris et al. 2016) and in raw fermented sausages (Lorencova et al. 2019), MAP could be considered as possible

57 foodborne pathogen.

A similar pathology in the intestinal tissue of patients with intestinal tuberculosis and paratuberculosis was described more than a century ago (Dalziel 1913). Recently, an association between MAP and Crohn's disease was shown, initiating a discussion about a possible relationship of MAP in Crohn`s pathogenesis (Alcedo et al. 2016). Johne`s and Crohn`s disease share clinical and histopathological similarities, MAP can survive standard pasteurization procedures and MAP antibodies can be detected in Crohn`s patients, where macrolide antibiotics ameliorate disease

64 (Kuenstner et al. 2017). In contrast, genotypes of MAP isolated from cattle and man are different, 
consistently be isolated from Crohn`s disease patients (Mendoza et al. 2009). Although MAP was

67 detected widespread in many farms and different countries, the incidence of Johne`s disease in

68 ruminants is marginal (Sergeant et al. 2019). Bacteria can survive for 2-10 years without causing

69 obvious symptoms of infection in cows (Hermon-Taylor 2000). As seen in cattle farms,

70 susceptibility to MAP infection differs in human populations (Eslami et al. 2019). This points to a

71 complex disease in which several pathogens, environmental factors and an inappropriate immune

72 response in genetically susceptible hosts participate in the cause of disease (Eslami et al. 2019).

73 Since an enhanced susceptibility of the host contributes to pathogenesis in other mycobacteria

74 associated diseases (e.g. tuberculosis) (Scriba et al. 2017), our aim wasto gain further information

75 about the interplay of MAP with the immune system in hosts with different immune capacities.

76 This is also of interest because in cattle, the MAP eradication programmes that are solely based on

77 hygiene management are not very successful (McAloon et al. 2019). This could indicate certain

78 reservoir cows that host and spread MAP without developing any clinical signs.

79 Little is known about the host-pathogen interaction of MAP and the immune system of its

80 hosts (Davis 2015). Functional differences in these responses could lead to aberrant reactions in

81 susceptible hosts (Davis 2015).

82 Recently, we detected a functionally different immune capacity in $22 \%$ of cows from different

83 herds in Germany using differential proteome analyses (Lutterberg et al. 2018). These cows differ

84 in their constitutive immune proteome and they regulate different master immune regulators upon

85 polyclonal immune cell stimulation. The phenotype is functionally correlated with an increased 
86 prevalence of mastitis, indicating an impact on the ability to fight infections (Lutterberg et al.

87 2018). Since the immune capacity of these cows clearly differs but the functional impact has to be

88 characterized more accurately in future studies, we designated them immune deviant (ID) cows.

89 All living microorganisms are exposed to changing environmental parameters that define their

90 habitats. Bacteria sense environmental changes and react to it with various stress response

91 mechanisms (Guo \& Gross 2014). To gain information about the pathogenic mechanisms of MAP

92 and how they respond to different immune response signals of their hosts, we co-incubated MAP

93 with primary peripheral blood derived leukocytes (PBL) of control and ID cows. Since the aim of

94 this study was a better understanding of the host-pathogen response, we analysed the changes in

95 the exoproteomes of MAP and the bovine peripheral blood derived lymphocytes.

96 The term exoproteome describes the protein content that can be found in the extracellular

97 proximity of a given biological system (Armengaud et al. 2012). These proteins arise from cellular

98 secretion, other protein export mechanisms or cell lysis, but only the most stable proteins in this

99 environment will remain abundant (Armengaud et al. 2012). These proteins play roles in the

100 organism's survival in extreme habitats such as saline environments (Rubiano-Labrador et al.

101 2015). Investigating the exoproteome of the pathogen and the secretome of PBL provides

102 expanded coverage of the repertoire of proteins secreted in the stress response of MAP to different

103 immune responses and this is essential for understanding respective mechanisms. Accordingly,

104 this study aimed at providing a better understanding of the interplay of Mycobacterium avium 
105 subsp. paratuberculosis (MAP) with the immune system at the proteome level to identify the

106 complex network of proteins involved in host-foodborne bacteria communication.

\section{2. Materials and Methods}

108 2.1. Mycobacterium avium subsp. paratuberculosis (MAP)

109 The bacterial strain used in this study was Mycobacterium avium subsp. paratuberculosis (DSM

110 44133), purchased from German Collection of Microorganisms and Cell Cultures (DSMZ,

111 Braunschweig, Germany). MAP were grown on Herrold`s egg yolk agar (HEYM) (BD

112 Biosciences, Heidelberg, Germany) for four weeks prior to harvesting for the co-incubation

113 experiment. MAP were yielded through rinsing the agar of the cultivation tubes with phosphate

114 buffered saline (PBS) and gentle scratching.

\section{2.2. PBL isolation of control and immune deviant cows}

116 Blood samples of cows were collected in tubes supplemented with 25.000 I.U. heparin. Blood was

117 then diluted 1:2 with PBS pH 7.2 and subsequently layered on density gradient separating solution

118 (Pancoll; PanBiotech, Aidenbach, Germany). After density gradient centrifugation (room

119 temperature, $290 \times \mathrm{g}, 25 \mathrm{~min}$, brake off), PBL were obtained from at the intermediate phase. Cells

120 were then washed $3 \mathrm{x}$ in $\mathrm{PBS}\left(4^{\circ} \mathrm{C}\right)$. Withdrawal of blood was permitted by the local authority

121 Regierung von Oberbayern, Munich, permit no. 55.2-1-54-2532.3-22-12. For determination of

122 control or ID status, PBL were tested in in vitro proliferation assays as described in (Lutterberg et

123 al. 2018). Respective animals were tested at least 11 times, before being assigned to control or ID 
124 status. The animals were from a MAP-free farm and were tested negative for MAP antibodies and

125 no MAP was detected in culture from feces.

\section{2.3. Co-incubation of MAP with primary bovine PBL}

127 Primary bovine PBL $\left(2 \times 10^{7}\right)$ of control and ID cows were cultivated in 6 well plates in $3 \mathrm{ml}$ RPMI

128 each. The same number of live MAP $\left(2 \times 10^{7} ; \mathrm{MOI}=1\right)$ were added for $48 \mathrm{~h}$ to one well, control

129 wells were not infected. After $48 \mathrm{~h}$, three technical replicates per experiment were centrifuged for

$13010 \mathrm{~min}$ at $350 \mathrm{xg}$ and the supernatants were filtered through $0,5 \mu \mathrm{m}$ filters (= exoproteome) and

131 stored at $-20^{\circ} \mathrm{C}$ until filter aided sample preparation (FASP). Cell pellets were lysed and total

132 protein content measured colorimetric with the Bradford assay (Bradford 1976).

\section{2.4. Proteolysis and LC-MS/MS mass spectrometry}

$13410 \mu \mathrm{g}$ total protein was digested with LysC and trypsin by filter-aided sample preparation (FASP)

135 as described in (Grosche et al. 2016). Acidified eluted peptides were analysed in the data-

136 dependent mode on a Q Exactive HF mass spectrometer (Thermo Fisher Scientific, Bremen,

137 Germany) online coupled to a UItimate 3000 RSLC nano-HPLC (Dionex). Samples were

138 automatically injected and loaded onto the C18 trap column and after 5 min eluted and separated

139 on the C18 analytical column $(75 \mu \mathrm{m}$ IDx15cm, Acclaim PepMAP $100 \mathrm{C} 18.100 \AA$ / size, LC

140 Packings, Thermo Fisher Scientific, Bremen, Germany) by a 90min non-linear acetonitrile

141 gradient at a flow rate of $250 \mathrm{nl} / \mathrm{min}$. MS spectra were recorded at a resolution of 60000 and after

142 each MS1 cycle, the 10 most abundant peptide ions were selected for fragmentation.

\section{2.5. Protein identification and label-free quantification}


144 Acquired MS spectra were imported into Progenesis software (version 2.5 Nonlinear Dynamics,

145 Waters) and analyzed as previously described (Hauck et al. 2012; Hauck et al. 2017). After

146 alignment, peak picking, exclusion of features with charge state of 1 and $>7$ and normalization,

147 spectra were exported as Mascot Generic files and searched against a database containing all

148 entries of Mycobacterium avium subspecies paratuberculosis from NCBI Protein database

149 combined with the Ensembl bovine database (version 80) with Mascot (Matrix Science, Version

150 2.5.1). Search parameters used were $10 \mathrm{ppm}$ peptide mass tolerance, $20 \mathrm{mmu}$ fragment mass

151 tolerance, one missed cleavage allowed, carbamidomethylation set as fixed modification, and

152 methionine oxidation and deamidation of asparagine and glutamine as variable modifications.

153 Mascot integrated decoy database search was set to a false discovery rate (FDR) of $1 \%$ when

154 searching was performed on the concatenated mgf files with a percolator ion score cut-off of 13

155 and an appropriate significance threshold p. Peptide assignment was reimported to Progenesis

156 Software. All unique peptides allocated to a protein were considered for quantification. Proteins

157 with a ratio of at least five-fold in normalized abundance between control and ID samples were

158 defined as differentially expressed.

\section{2.6. Enriched pathway analyses}

160 Abundances of the identified proteins were defined as differentially expressed based on the

161 threshold of protein abundance ratio and their assignement to MAP or bovine exoproteome. Venn

162 diagram was made with open source tool: http://bioinformatics.psb.ugent.be/webtools/Venn/. The

163 protein-protein interaction network of differentially-accumulated proteins was analysed with 
164 GeneRanker of Genomatix Pathway System (GePS) software (version 3.10; Intrexon

165 Bioinformatics GmbH, Munich, Germany; settings: Orthologous genes from H. sapiens were used

166 for this ranking, species bovine, analysed were proteins with $\geq 5$-fold change). Hierarchical

167 clustering and enrichment analysis of biological pathways were conducted with open source

168 software ShinyGO v0.50: http://ge-lab.org/go/ (Ge \& Jung 2018), p-value cutoff (FDR) was set to

169 0.05. ShinyGO uses gene ontology (GO) annotation and gene ID mapping of animal and plant

170 genomes in Ensembl BioMart and in addition archaeal, bacterial and eukaryotic genomes based

171 on STRING-db v10. Additional pathway data are collected for some model species from difference

172 sources. Since many GO terms are related or even redundant, the relatedness was visualized with

173 the hierarchical clustering tree and network, where related GO terms are grouped together based

174 on how many genes they share. The size of the solid circle corresponds to the enrichment FDR.

175 In the network analysis, each node represented an enriched GO term. Related GO terms were

176 connected by a line, whose thickness reflects percent of overlapping genes. Size of the node

177 corresponded to number of genes.

178

179 3. Results

180 3.1. Differentially abundant proteins in secrotomes of control and immune deviant bovine

181 peripheral blood lymphocytes in response to co-incubation with MAP

182 We investigated the immune response of primary PBL isolated from control and immune deviant 
183 animals. After 48 hours of co-incubation with live MAP, we harvested the mixed secretomes and

184 exoproteomes of PBL and MAP and analysed them with mass spectrometry. Overall, we identified

185826 proteins ( 811 bovine and 15 MAP proteins). Cluster analysis confirmed significant differences

186 in protein abundances between PBL of control and ID cow in host-pathogen response (Figure 1).

187 In secretome of control cow, 90 proteins were differentially upregulated (Figure 1, $\geq 5$-fold change

188 of expression, blue circle) in contrast to 38 proteins that were higher abundant in ID cow (Figure

189 1, light red circle).

190

3.2. Different biological pathways were regulated in immune deviant versus control bovine

191 PBL in response to MAP

192 Interpretation of large protein sets can be performed through enrichment analyses, using published

193 information for examination of overrepresentation of a known set of genes within the input gene

194 list (Ge \& Jung 2018; Merico et al. 2010). Since many gene ontology (GO) terms are related or

195 redundant, we used a hierarchical clustering tree and network analysis (ShinyGO v.050 (Ge \&

196 Jung 2018)). The top regulated biological process pathways in the secretome/excretome of the

197 control were all related to RNA splicing (Figure 2A). The top regulated immune pathways were

198 cellular immune responses of various leukocyte subsets, chemotaxis and the reaction to IL-12

199 (Figure 2A).

200 In contrast, in the secretome/excretome of ID PBL, the top regulated pathways were response to

201 stress and immune system process (Figure 2B). The enriched immune pathways comprised distinct 
202 routes of immune response in ID PBL, focusing on closely related positive regulations of cellular

203 functions, complement activation and humoral immune response (Figure 2B).

204 Visualization of network clearly indicates two major regulated networks in control PBL's

205 secretome (Figure 3A) and one distinct, major enriched network in ID proteins (Figure 3B).

\subsection{GroEl1 and DnAK were differentially abundant in MAPs interacting with different hosts}

In the MAP exoproteome, although small in overall numbers, different protein abundances were

also detectable. The two most notable were the protein GroE11, upregulated in MAP co-incubated

with control PBL, versus the protein DnaK, which was upregulated in MAP co-incubated with ID

210 PBL. Other MAP proteins were differentially up or down regulated, but not to as great an extent

211 as GroE11 or DnaK, as noted in Table 1.

\section{4. Discussion}

213 Mycobacterium avium subsp. paratuberculosis (MAP) could be a foodborne pathogen and has

214 been discussed in association with several human diseases (Cossu et al. 2019; Pierce 2018; Sechi

215 \& Dow 2015). MAP has been identified I in patients with inflammatory bowel diseases like

216 Crohn's disease and ulcerative colitis, as well as autoimmune diseases like type 1 diabetes,

217 multiple sclerosis, rheumatoid arthritis and Hashimoto's thyroiditis (Garvey 2018), but so far, a

218 causal association has not yet been proven in any of these cases. Since MAP can survive many of

219 the standard techniques of food decontamination (e.g. pasteurization), they are regularly found 
220 alive in pasteurized milk (Gerrard et al. 2018) and in dried dairy products such as powdered infant

221 formula (Botsaris et al. 2016). If MAP organisms play a role in the pathogenesis of human diseases,

222 we think that this must be associated with a certain type of susceptibility in these human hosts.

223 MAP is ubiquitously found in milk and meat while only a minor proportion of consumers (if at

224 all) is affected by MAP-associated diseases. The same is true for cows: while they are often in

225 contact with MAP, resulting in high frequencies of seropositive animals - approximately $20 \%$ and

226 at least 3-5\% in several countries (Boelaert et al. 2000; Nielsen \& Toft 2009) - Johne`s disease

227 incidence is very rare. For example, a total of 232 clinical cases of Johne`s disease were reported

228 in Ireland from 1995 to 2002 (Kennedy et al. 2014), yielding an average annual rate of

229 approximately $0.0005 \%$, given a cattle population of six million (Maher et al. 2008). A study

230 examining environmental samples from 362 dairy farms located in all 10 provinces of Canada for

231 detection of MAP by culture revealed true prevalence estimates of $66 \%$ for farms in Western

232 Canada, 54\% in Ontario, 24\% in Québec, and 47\% in Atlantic Canada (Corbett et al. 2018).

233 It is known from infection with Mycobacterium tuberculosis (MTB), that there is a $10 \%$

234 probability that the host will develop active tuberculosis and the bacterium may invade multiple

235 organs (Zhai et al. 2019). Although 9 million new cases of active tuberculosis are still reported

236 annually, an estimated one-third of the world is infected with MTB while remaining asymptomatic,

237 defined as latent TB (Dye et al. 1999). Among the individuals with latent TB, only 5-10\% will

238 develop active tuberculosis disease in course of their lifetime, because they effectively control the

239 infection through their immune response (Dye et al. 1999). This immune response after MTB 
240 infection is highly complex as the bacteria have intricate immune escape mechanisms (Zhai et al.

241 2019).

242 For MAP, little is known about host-pathogen reactions in general, and whether different immune

243 responses exist, but a thorough examination of the respective mechanisms is of major importance

244 to obtain functional data that will allow a better understanding and a substantiated risk assessment.

245 In the post-genomic era, proteomics represents a key discipline to perform in depth studies and

246 identify the complex network of proteins involved in such host-bacteria communication. In this

247 study, we analysed the exoproteomes/secretomes of MAP and host cow PBL with known,

248 functionally different immune capacities (Lutterberg et al. 2018) using differential proteome

249 analyses after co-incubation in vitro. Interestingly, there were significant differences in protein

250 abundances secreted from control and ID PBL. Ninety proteins were $\geq 5$ fold higher abundant in

251 control PBL after interaction with MAP. In the control, the top regulated immune pathways

252 described cell activation and chemotaxis of leukocytes as well as IL-12 mediated signalling

253 pathways. For MAP it was shown, that IL-12 transcription is increased in infected bovine

254 macrophages within 6 hours (Weiss et al. 2002), probably to enhance the developing T cell

255 response (Bannantine et al. 2015). Later, the in vitro challenged monocytes-derived macrophages

256 from healthy cows enhanced production of the anti-inflammatory cytokine interleukin-10 (IL-10)

257 as measured by qRT-PCR (Abenda et al. 2013). This counteracted initial IL-12 production

258 (Abenda et al. 2013) and high levels of IL-10 in paratuberculosis were shown promote the survival

259 of MAP (Hussain et al. 2016). Further, in THP1 cells, a human monocytic cell line, IL-12B gene 
expression was downregulated immediately after in vitro infection with MAP (Motiwala et al.

261 2006). To our knowledge, the role of IL-12 in MAP infections of cows has not been analysed so

262 far on protein level (Abenda et al. 2013), but the IL-12 associated immune response should also

263 be protective. In tuberculosis it was shown that the induction of protective IFN- $\gamma$ T cell responses

264 against primary $M$. tuberculosis infection clearly depends on IL-12 (Khader et al. 2006). Mice

265 lacking IL-12p40 cannot control the growth of MTB bacterial infection (Cooper et al. 1997). These

266 findings in mouse models were confirmed in man, where IL-12 was shown to be critical for

267 preventing tuberculosis (Alcaïs et al. 2005). Therefore, we hypothesize that secretion of IL-12

268 indicates a protective immune response against MAP infection in control PBL. But, further

269 investigation about the role of IL-12 in MAP infection is needed, probabaly in naturally infected

270 animals that cope differentially with clearing of MAP from their body.

271 In ID PBL on the other hand, CCR4-NOT transcription complex, subunit 1 (CNOT1) was detected

272 as highly abundant protein (supplemental table 1). This novel finding of CNOT1 regulation in the

273 bovine immune system is very interesting, because CCR4-NOT complex members have recently

274 been shown to function as regulators ensuring repression of the MHC class II locus in human cell

275 lines (Rodríguez-Gil et al. 2017). Poor MHC class II expression can cause autoimmune or

276 infectious diseases, since MHCII is indispensable for adequate immune responses (Rodríguez-Gil

277 et al. 2017). Additionally, CNOT proteins also contribute to the downregulation of MHC class I

278 gene expression by influencing transcription and mRNA degradation (Yang et al. 2016). There is

279 evidence that mycobacteria interfere with the synthesis and expression of MHC class I and II 
280 molecules and their participation in antigen processing as a mechanism of immune evasion

281 (Harding \& Boom 2010; Noss et al. 2000; Tufariello et al. 2003). Experimentally MAP exposed

282 Merino sheep that were monitored during course of disease revealed an important role for MHC

283 class I and II gene expression and disease outcome (Purdie et al. 2019). There was a prolonged

284 overall inhibition of expression of MHC class I genes the multibacillary and the paucibacillary

285 cohorts, promoting enhanced survival of the intracellular pathogen MAP in infected sheep (Purdie

286 et al. 2019). A modulation of MHC genes was also shown in a transcriptomic analysis of

287 experimentally infected Holstein-Friesian calves (David et al. 2014a; David et al. 2014b) and very

288 early differential regulation of MHC genes in young, MAP exposed cattle (Purdie et al. 2012).

289 Further investigation is needed to analyse a possible connection of CNOT1 to the immune evasion

290 mechanisms happening in MAP infections, especially since it is not known so far, whether the

291 alterations to MHC expression is driven by the pathogen or by the host (Purdie et al. 2012).

292 Enriched network analyses of secreted proteins from ID PBL revealed further major different

293 functions of the 38 differentially abundant proteins (Figure 3B). Members of complement

294 activation pathway were enriched in ID PBL. We think the regulated candidates in ID PBL merit

295 further investigation in future studies to clarify whether they indicate an immune response in

296 favour of MAP infection or just another way to successfully fight mycobacterial infections.

297 Interestingly, in the MAP exoproteome (although small in overall numbers) different protein

298 abundances were also detectable. Exoproteomes arise from cellular secretion, other protein export

299 mechanisms or cell lysis, but only the most stable proteins in this environment will remain 
300 abundant (Armengaud et al. 2012). In MAP co-incubated with control PBL, GroEL1 showed 6-

301 fold higher abundance. GroEL1 belongs to the family of $60 \mathrm{kDa}$ heat shock proteins, also known

302 as Cpn60s (GroELs) which are components of the essential protein folding machinery of the cell,

303 but are also dominant antigens in many infectious diseases (Sharma et al. 2016). GroEL1 from

304 MAP is highly immunogenic for cows (Yang et al. 2016). The exact function of GroEL1 in MAP

305 is not clarified so far, but it is highly similar to the respective protein in MTB (Rv3417c), where

306 GroEL1 is important for bacterial survival under low aeration by affecting the expression of genes

307 known for hypoxia response (Sharma et al. 2016). From co-cultivation of MAP with ID PBL, on

308 the other hand, DnaK emerged as differentially abundant protein. DnaK is a HSP70 family

309 chaperone protein with essential function in stress induced protein refolding and DnaK loss is

310 accompanied by disruption of membrane structure and increased cell permeability (Fay \&

311 Glickman 2014). DnaK is essentially required for cell growth in mycobacteria due to a lack of

312 redundancy with other chaperone systems (Fay \& Glickman 2014). This finding from MAP - ID

313 PBL co-cultivation points to regulation of important survival mechanisms in MAP. However, these

314 results must be interpreted with care because our analysed MAP exoproteome only comprised 15

315 proteins.

316 Our data provide novel information about MAP-leukocyte interaction, adding to a more

317 comprehensive picture of host-pathogen interactions. Co-incubation of MAP with cells from

318 animals with different immune capacities led to significant differences in PBL secretomes and

319 different immunological pathways enhanced in the hosts. In exoproteomes of respective MAPs, 
320 GroEL1 and DnaK were differentially abundant. These analyses gave a deeper insight into the

321 different responses of host PBL and MAP bacteria.

\section{Conclusions:}

323 In this study, several novel proteins were identified with changed abundance in host-pathogen

324 interaction. These candidates merit further investigations in the future to clarify their functional

325 role in infection control.

326 Acknowledgments:

327 The authors would like to thank Barbara Amann for excellent technical support.

328 Author Contributions: C.D. conceived and designed the experiments; K.K., S.H., A.S. and C.H.

329 performed the experiments; K.K., S.H., R.D., E.M. and C.D. analyzed the data; C.D. wrote the

330 manuscript. All authors critically read the manuscript and approved the final version to be

331 published.

332 Funding: The IGF Project $18388 \mathrm{~N}$ of the FEI was supported via AiF within the program for

333 promoting the Industrial Collective Research (IGF) of the German Ministry of Economic Affairs

334 and Energy (BMWi), based on a resolution of the German Parliament.

335 Conflicts of Interest: The authors declare no conflict of interest.

\section{Abbreviations}

337 CCR4 CCR4-NOT transcription complex, subunit 1

338 FASP Filter-aided sample preparation 
339 ID Immune deviant

340 IL- Interleukin

341 HEYM Herrold`s egg yolk agar

342 MAP Mycobacterium avium subsp. paratuberculosis

343 MTB Mycobacterium tuberculosis

344 PBL Peripheral blood derived lymphocytes

345 PBS Phosphate buffered saline

346 References

347

348 Kuenstner JT, Naser S, Chamberlin W, Borody T, Graham DY, McNees A, Hermon-Taylor J, Hermon-Taylor A, Dow

349

350

CT, Thayer W, et al: The consensus from the Mycobacterium Avium Ssp. paratuberculosis (MAP) conference 2017. Front Public Health 2017;5:208.

351

Abenda, \#xf1, o N, Juste RA, and Alonso-Hearn M. 2013. Anti-Inflammatory and Antiapoptotic Responses to Infection:

352

A Common Denominator of Human and Bovine Macrophages Infected with Mycobacterium avium Subsp.

353 paratuberculosis. Biomed Res Int 2013:7. 10.1155/2013/908348

354

Alcaïs A, Fieschi C, Abel L, and Casanova J-L. 2005. Tuberculosis in children and adults: two distinct genetic diseases. The Journal of Experimental Medicine 202:1617-1621. 10.1084/jem.20052302

356

Alcedo KP, Thanigachalam S, and Naser SA. 2016. RHB-104 triple antibiotics combination in culture is bactericidal and

357

358 should be effective for treatment of Crohn's disease associated with Mycobacterium paratuberculosis. Gut Pathogens 8:32-32. 10.1186/s13099-016-0115-3

359

Armengaud J, Christie-Oleza JA, Clair G, Malard V, and Duport C. 2012. Exoproteomics: exploring the world around

360 biological systems. Expert Review of Proteomics 9:561-575. 10.1586/epr.12.52

361

Bannantine JP, Stabel JR, Laws E, D Cardieri MC, and Souza CD. 2015. Mycobacterium avium Subspecies paratuberculosis Recombinant Proteins Modulate Antimycobacterial Functions of Bovine Macrophages. PLoS One 10:e0128966-e0128966. 10.1371/journal.pone.0128966

364

Boelaert F, Walravens K, Biront P, Vermeersch JP, Berkvens D, and Godfroid J. 2000. Prevalence of paratuberculosis 365 (Johne's disease) in the Belgian cattle population. Veterinary Microbiology 77:269-281. https://doi.org/10.1016/S0378-1135(00)00312-6

367

Botsaris G, Swift BMC, Slana I, Liapi M, Christodoulou M, Hatzitofi M, Christodoulou V, and Rees CED. 2016. Detection of viable Mycobacterium avium subspecies paratuberculosis in powdered infant formula by phage- 
369

370

371

372

373

374

375

376

377

378

379

380

381

382

383

384

385

386

387

388

389

390

391

392

393

394

395

396

397

398

399

400

401

402

403

404

405

406
PCR and confirmed by culture. International Journal of Food Microbiology 216:91-94. https://doi.org/10.1016/j.ijfoodmicro.2015.09.011

Bradford MM. 1976. A rapid and sensitive method for the quantitation of microgram quantities of protein utilizing the principle of protein-dye binding. Anal Biochem 72:248-254. 10.1006/abio.1976.9999

Cooper AM, Magram J, Ferrante J, and Orme IM. 1997. Interleukin 12 (IL-12) is crucial to the development of protective immunity in mice intravenously infected with mycobacterium tuberculosis. The Journal of Experimental Medicine 186:39-45.

Corbett CS, Naqvi SA, Bauman CA, De Buck J, Orsel K, Uehlinger F, Kelton DF, and Barkema HW. 2018. Prevalence of $<$ em $>$ Mycobacterium avium $<$ em $>$ ssp. $<$ em $>$ paratuberculosis $</$ em $>$ infections in Canadian dairy herds. Journal of Dairy Science 101:11218-11228. 10.3168/jds.2018-14854

Cossu D, Yokoyama K, Sakanishi T, Momotani E, and Hattori N. 2019. Adjuvant and antigenic properties of $<$ em $>$ Mycobacterium avium $</$ em $>$ subsp. $<$ em $>$ paratuberculosis $</$ em $>$ on experimental autoimmune encephalomyelitis. Journal of Neuroimmunology. 10.1016/j.jneuroim.2019.01.013

Dalziel TK. 1913. Chronic Interstitial Enteritis. The British Medical Journal 2:1068-1070.

David J, Barkema HW, Guan LL, and De Buck J. 2014a. Gene-expression profiling of calves 6 and 9 months after inoculation with Mycobacterium avium subspecies paratuberculosis. Veterinary Research 45:96-96. 10.1186/s13567-014-0096-5

David J, Barkema HW, Mortier R, Ghosh S, Guan LL, and De Buck J. 2014b. Gene expression profiling and putative biomarkers of calves 3 months after infection with Mycobacterium avium subspecies paratuberculosis. Veterinary Immunology and Immunopathology 160:107-117. https://doi.org/10.1016/j.vetimm.2014.04.006

Davis WC. 2015. On deaf ears, Mycobacterium avium paratuberculosis in pathogenesis Crohn's and other diseases. World journal of gastroenterology 21:13411-13417. 10.3748/wjg.v21.i48.13411

Dye C, Scheele S, Dolin P, Pathania V, Raviglione MC, for the WHOGS, and Monitoring P. 1999. Global Burden of Tuberculosis: Estimated Incidence, Prevalence, and Mortality by Country. JAMA 282:677-686. 10.1001/jama.282.7.677

Eslami M, Shafiei M, Ghasemian A, Valizadeh S, Al-Marzoqi AH, Shokouhi Mostafavi SK, Nojoomi F, and Mirforughi SA. 2019. Mycobacterium avium paratuberculosis and Mycobacterium avium complex and related subspecies as causative agents of zoonotic and occupational diseases. Journal of Cellular Physiology 0. doi:10.1002/jcp.28076

Fay A, and Glickman MS. 2014. An essential nonredundant role for mycobacterial DnaK in native protein folding. PLoS Genet 10:e1004516-e1004516. 10.1371/journal.pgen.1004516

Garvey M. 2018. Mycobacterium avium subspecies paratuberculosis: A possible causative agent in human morbidity and risk to public health safety. Open veterinary journal 8:172-181. 10.4314/ovj.v8i2.10

Ge S, and Jung D. 2018. ShinyGO: a graphical enrichment tool for animals and plants. bioRxiv:315150. 10.1101/315150

Gerrard ZE, Swift BMC, Botsaris G, Davidson RS, Hutchings MR, Huxley JN, and Rees CED. 2018. Survival of Mycobacterium avium subspecies paratuberculosis in retail pasteurised milk. Food Microbiology 74:57-63. https://doi.org/10.1016/j.fm.2018.03.004

Grosche A, Hauser A, Lepper MF, Mayo R, von Toerne C, Merl-Pham J, and Hauck SM. 2016. The Proteome of Native Adult Müller Glial Cells From Murine Retina. Mol Cell Proteomics 15:462-480. 10.1074/mcp.M115.052183

PeerJ reviewing PDF | (2019:08:40175:1:2:NEW 17 Oct 2019) 
407 Guo MS, and Gross CA. 2014. Stress-induced remodeling of the bacterial proteome. Curr Biol 24:R424-R434. $408 \quad$ 10.1016/j.cub.2014.03.023

409

410

411

412

413

414

415

416

417

418

419

420

421

422

423

424

425

426

427

428

429

430

431

432

433

434

435

436

437

438

439

440

441

442

443

444

445

Harding CV, and Boom WH. 2010. Regulation of antigen presentation by Mycobacterium tuberculosis: a role for Tolllike receptors. Nature reviews Microbiology 8:296-307. 10.1038/nrmicro2321

Hauck SM, Hofmaier F, Dietter J, Swadzba ME, Blindert M, Amann B, Behler J, Kremmer E, Ueffing M, and Deeg CA. 2012. Label-free LC-MSMS analysis of vitreous from autoimmune uveitis reveals a significant decrease in secreted Wnt signalling inhibitors DKK3 and SFRP2. J Proteomics 75:4545-4554. 10.1016/j.jprot.2012.04.052

Hauck SM, Lepper MF, Hertl M, Sekundo W, and Deeg CA. 2017. Proteome Dynamics in Biobanked Horse Peripheral Blood Derived Lymphocytes (PBL) with Induced Autoimmune Uveitis. PROTEOMICS 17:1700013. doi:10.1002/pmic.201700013

Hermon-Taylor J. 2000. Mycobacterium avium subspecies paratuberculosis in the causation of Crohn's disease. World journal of gastroenterology 6:630-632. 10.3748/wjg.v6.i5.630

Hobmaier BF, Lutterberg K, Kleinwort KJH, Mayer R, Hirmer S, Amann B, Hölzel C, Märtlbauer EP, and Deeg CA. 2019. Characterization of plant lectins for their ability to isolate Mycobacterium avium subsp. paratuberculosis from milk. Food Microbiology 82:231-239. https://doi.org/10.1016/j.fm.2019.02.009

Hussain T, Shah SZA, Zhao D, Sreevatsan S, and Zhou X. 2016. The role of IL-10 in Mycobacterium avium subsp. paratuberculosis infection. Cell communication and signaling : CCS 14:29-29. 10.1186/s12964-016-0152-z

Kennedy AE, Da Silva AT, Byrne N, Govender R, MacSharry J, O'Mahony J, and Sayers RG. 2014. The Single Intradermal Cervical Comparative Test Interferes with Johne's Disease ELISA Diagnostics. Frontiers in Immunology 5:564-564. 10.3389/fimmu.2014.00564

Khader SA, Partida-Sanchez S, Bell G, Jelley-Gibbs DM, Swain S, Pearl JE, Ghilardi N, Desauvage FJ, Lund FE, and Cooper AM. 2006. Interleukin 12p40 is required for dendritic cell migration and T cell priming after Mycobacterium tuberculosis infection. The Journal of Experimental Medicine 203:1805-1815. 10.1084/jem.20052545

Kuenstner JT, Naser S, Chamberlin W, Borody T, Graham DY, McNees A, Hermon-Taylor J, Hermon-Taylor A, Dow CT, Thayer W, Biesecker J, Collins MT, Sechi LA, Singh SV, Zhang P, Shafran I, Weg S, Telega G, Rothstein R, Oken H, Schimpff S, Bach H, Bull T, Grant I, Ellingson J, Dahmen H, Lipton J, Gupta S, Chaubey K, Singh M, Agarwal P, Kumar A, Misri J, Sohal J, Dhama K, Hemati Z, Davis W, Hier M, Aitken J, Pierce E, Parrish N, Goldberg N, Kali M, Bendre S, Agrawal G, Baldassano R, Linn P, Sweeney RW, Fecteau M, Hofstaedter C, Potula R, Timofeeva O, Geier S, John K, Zayanni N, Malaty HM, Kahlenborn C, Kravitz A, Bulfon A, Daskalopoulos G, Mitchell H, Neilan B, Timms V, Cossu D, Mameli G, Angermeier P, Jelic T, Goethe R, Juste RA, and Kuenstner L. 2017. The Consensus from the Mycobacterium avium ssp. paratuberculosis (MAP) Conference 2017. Frontiers in public health 5:208-208. 10.3389/fpubh.2017.00208

Li L, Bannantine JP, Campo JJ, Randall A, Grohn YT, Katani R, Schilling M, Radzio-Basu J, and Kapur V. 2017. Identification of sero-reactive antigens for the early diagnosis of Johne's disease in cattle. PLoS One 12:e0184373. 10.1371/journal.pone.0184373

Li L, Katani R, Schilling M, and Kapur V. 2016. Molecular Epidemiology of Mycobacterium avium subsp. paratuberculosis on Dairy Farms. Annual Review of Animal Biosciences 4:155-176. 10.1146/annurev-animal021815-111304

PeerJ reviewing PDF | (2019:08:40175:1:2:NEW 17 Oct 2019) 
446 Lorencova A, Babak V, Kralova A, and Borilova G. 2019. Survival of Mycobacterium avium subsp. paratuberculosis in

447

448

449

450

451

452

453

454

455

456

457

458

459

460

461

462

463

464

465

466

467

468

469

470

471

472

473

474

475

476

477

478

479

480

481

482

483 raw fermented sausages during production and storage. Meat Science 155:20-26. https://doi.org/10.1016/j.meatsci.2019.04.023

Lutterberg K, Kleinwort KJH, Hobmaier BF, Hauck SM, Nüske S, Scholz AM, and Deeg CA. 2018. A Functionally Different Immune Phenotype in Cattle Is Associated With Higher Mastitis Incidence. Frontiers in Immunology 9:2884-2884. 10.3389/fimmu.2018.02884

Machado G, Kanankege K, Schumann V, Wells S, Perez A, and Alvarez J. 2018. Identifying individual animal factors associated with Mycobacterium avium subsp. paratuberculosis (MAP) milk ELISA positivity in dairy cattle in the Midwest region of the United States. BMC Veterinary Research 14:28. 10.1186/s12917-018-1354-y

Maher P, Good M, and More S. 2008. Trends in cow numbers and culling rate in the Irish cattle population, 2003 to 2006. Irish veterinary journal 61:455-463. 10.1186/2046-0481-61-7-455

McAloon CG, Roche S, Ritter C, Barkema HW, Whyte P, More SJ, O’Grady L, Green MJ, and Doherty ML. 2019. A review of paratuberculosis in dairy herds - Part 2: On-farm control. The Veterinary Journal 246:54-58. https://doi.org/10.1016/j.tvj1.2019.01.009

Mendoza JL, Lana R, and Díaz-Rubio M. 2009. Mycobacterium avium subspecies paratuberculosis and its relationship with Crohn's disease. World journal of gastroenterology 15:417-422. 10.3748/wjg.15.417

Merico D, Isserlin R, Stueker O, Emili A, and Bader GD. 2010. Enrichment Map: A Network-Based Method for GeneSet Enrichment Visualization and Interpretation. PLoS One 5:e13984. 10.1371/journal.pone.0013984

Motiwala AS, Janagama HK, Paustian ML, Zhu X, Bannantine JP, Kapur V, and Sreevatsan S. 2006. Comparative Transcriptional Analysis of Human Macrophages Exposed to Animal and Human Isolates of $<\mathrm{em}>$ Mycobacterium avium $</ \mathrm{em}>$ Subspecies $<\mathrm{em}>$ paratuberculosis $</ \mathrm{em}>$ with Diverse Genotypes. Infection and Immunity 74:6046-6056. 10.1128/iai.00326-06

Nielsen SS, and Toft N. 2009. A review of prevalences of paratuberculosis in farmed animals in Europe. Preventive Veterinary Medicine 88:1-14. https://doi.org/10.1016/j.prevetmed.2008.07.003

Noss EH, Harding CV, and Boom WH. 2000. Mycobacterium tuberculosis Inhibits MHC Class II Antigen Processing in Murine Bone Marrow Macrophages. Cellular Immunology 201:63-74. https://doi.org/10.1006/cimm.2000.1633

Pierce ES. 2018. Could Mycobacterium avium subspecies paratuberculosis cause Crohn's disease, ulcerative colitis... and colorectal cancer? Infectious Agents and Cancer 13:1. 10.1186/s13027-017-0172-3

Purdie AC, Plain KM, Begg DJ, de Silva K, and Whittington RJ. 2012. Expression of genes associated with the antigen presentation and processing pathway are consistently regulated in early Mycobacterium avium subsp. paratuberculosis infection. Comparative Immunology, Microbiology and Infectious Diseases 35:151-162. https://doi.org/10.1016/j.cimid.2011.12.007

Purdie AC, Plain KM, Begg DJ, de Silva K, and Whittington RJ. 2019. Gene expression profiles during subclinical Mycobacterium avium subspecies paratuberculosis infection in sheep can predict disease outcome. Scientific Reports 9:8245. 10.1038/s41598-019-44670-w

Rodríguez-Gil A, Ritter O, Saul VV, Wilhelm J, Yang C-Y, Grosschedl R, Imai Y, Kuba K, Kracht M, and Schmitz ML. 2017. The CCR4-NOT complex contributes to repression of Major Histocompatibility Complex class II transcription. Scientific Reports 7:3547-3547. 10.1038/s41598-017-03708-7

Peer) reviewing PDF | (2019:08:40175:1:2:NEW 17 Oct 2019) 
484 Rubiano-Labrador C, Bland C, Miotello G, Armengaud J, and Baena S. 2015. Salt Stress Induced Changes in the

485

486

487

488

489

490

491

492

493

494

495

496

497

498

499

500

501

502

503

504

505

506

507

508

509

510

511

512

513

514
Exoproteome of the Halotolerant Bacterium Tistlia consotensis Deciphered by Proteogenomics. PLoS One 10:e0135065-e0135065. 10.1371/journal.pone.0135065

Scriba TJ, Coussens AK, and Fletcher HA. 2017. Human Immunology of Tuberculosis. Microbiology Spectrum 5. doi:10.1128/microbiolspec.ТВTB2-0016-2016

Sechi LA, and Dow CT. 2015. Mycobacterium avium ss. paratuberculosis Zoonosis - The Hundred Year War - Beyond Crohn's Disease. Frontiers in Immunology 6. 10.3389/fimmu.2015.00096

Sergeant ESG, McAloon CG, Tratalos JA, Citer LR, Graham DA, and More SJ. 2019. Evaluation of national surveillance methods for detection of Irish dairy herds infected with <em>Mycobacterium avium</em> ssp. $<$ em>paratuberculosis</em>. Journal of Dairy Science 102:2525-2538. 10.3168/jds.2018-15696

Sharma A, Rustad T, Mahajan G, Kumar A, Rao KVS, Banerjee S, Sherman DR, and Mande SC. 2016. Towards understanding the biological function of the unusual chaperonin Cpn60.1 (GroEL1) of Mycobacterium tuberculosis. Tuberculosis 97:137-146. https://doi.org/10.1016/j.tube.2015.11.003

Sweeney RW. 2011. Pathogenesis of Paratuberculosis. Veterinary Clinics of North America: Food Animal Practice 27:537546. https://doi.org/10.1016/j.cvfa.2011.07.001

Tufariello JM, Chan J, and Flynn JL. 2003. Latent tuberculosis: mechanisms of host and bacillus that contribute to persistent infection. The Lancet Infectious Diseases 3:578-590. 10.1016/S1473-3099(03)00741-2

Weiss DJ, Evanson OA, Moritz A, Deng MQ, and Abrahamsen MS. 2002. Differential responses of bovine macrophages to Mycobacterium avium subsp. paratuberculosis and Mycobacterium avium subsp. avium. Infection and Immunity 70:5556-5561. 10.1128/IAI.70.10.5556-5561.2002

Yamamoto T, Murai K, Hayama Y, Kobayashi S, Nagata R, Kawaji S, Osaki M, Sakakibara S-i, and Tsutsui T. 2018. Evaluation of fecal shedding and antibody response in dairy cattle infected with paratuberculosis using national surveillance data in Japan. Preventive Veterinary Medicine 149:38-46. https://doi.org/10.1016/j.prevetmed.2017.10.009

Yang C-Y, Ramamoorthy S, Boller S, Rosenbaum M, Rodriguez Gil A, Mittler G, Imai Y, Kuba K, and Grosschedl R. 2016. Interaction of CCR4-NOT with EBF1 regulates gene-specific transcription and mRNA stability in B lymphopoiesis. Genes E Development 30:2310-2324. 10.1101/gad.285452.116

Zhai W, Wu F, Zhang Y, Fu Y, and Liu Z. 2019. The Immune Escape Mechanisms of Mycobacterium Tuberculosis. International Journal of Molecular Sciences 20:340. 10.3390/ijms20020340 


\section{Table $\mathbf{1}$ (on next page)}

Regulation of MAP proteins identified in secretomes/exoproteomes after co-incubation with control and ID PBL

Regulation of MAP proteins identified in secretomes/exoproteomes after co-incubation with control and ID PBL. 


\begin{tabular}{|c|c|c|c|c|}
\hline & Accession & $\begin{array}{l}\text { Gene } \\
\text { symbol }\end{array}$ & Description & $\begin{array}{l}\text { Ratio } \\
\text { MAP } \\
\text { Ctr/ID }\end{array}$ \\
\hline 1 & AAS06815 & GroEL1 & $\begin{array}{l}\text { pep:novel } \\
\text { chromosome:GCA_000007865.1:Chromosome:473 } \\
\text { 3338:4734954:1 gene:MAP_4265 } \\
\text { transcript:AAS06815 description:"'GroEL1"'" }\end{array}$ & 6,07 \\
\hline 2 & ETB04387 & $\begin{array}{l}\text { F0F1 ATP } \\
\text { synthase } \\
\text { subunit } \\
\text { alpha }\end{array}$ & $\begin{array}{l}\text { pep:novel } \\
\text { supercontig:GCA_000504785.1:contig000131:9486: } \\
\text { 11150:1 gene:O979_07265 transcript:ETB04387 } \\
\text { description:"'F0F1 ATP synthase subunit alpha"'" }\end{array}$ & 3,26 \\
\hline 3 & ETB05569 & $\begin{array}{l}\text { DNA- } \\
\text { binding } \\
\text { protein }\end{array}$ & $\begin{array}{l}\text { pep:novel } \\
\text { supercontig:GCA_000504785.1:contig000072:8572: } \\
\text { 9225:1 gene:O979_04085 transcript:ETB05569 } \\
\text { description:"'DNA-binding protein"'" }\end{array}$ & 2,47 \\
\hline 4 & AAS06727 & RplN & $\begin{array}{l}\text { pep:novel } \\
\text { chromosome:GCA_000007865.1:Chromosome:465 } \\
\text { 2017:4652385:1 gene:MAP_4177 } \\
\text { transcript:AAS06727 description:"'"RplN"'" }\end{array}$ & 2,34 \\
\hline 5 & $\begin{array}{l}\text { AAS06486; } \\
\text { ELP44387; } \\
\text { ETB08817 }\end{array}$ & GroEL2 & $\begin{array}{l}\text { pep:novel } \\
\text { chromosome:GCA_000007865.1:Chromosome:439 } \\
\text { 5922:4397547:1 gene:MAP_3936 } \\
\text { transcript:AAS06486 description:"'GroEL2"'" }\end{array}$ & 1,12 \\
\hline 6 & AAS06693 & Tuf & $\begin{array}{l}\text { pep:novel } \\
\text { chromosome:GCA_000007865.1:Chromosome:462 } \\
\text { 0946:4622136:1 gene:MAP_4143 } \\
\text { transcript:AAS06693 description:"'"Tuf"'" }\end{array}$ & 0,88 \\
\hline 7 & ЕTB02420 & $\begin{array}{l}\text { enoyl-CoA } \\
\text { hydratase }\end{array}$ & $\begin{array}{l}\text { pep:novel } \\
\text { supercontig:GCA_000504785.1:contig000238:14619 } \\
\text { :15410:1 gene:O979_11400 transcript:ETB02420 } \\
\text { description:"'enoyl-CoA hydratase"'" }\end{array}$ & 0,86 \\
\hline 8 & ETB00930 & $\begin{array}{l}\text { 2- } \\
\text { isopropylm } \\
\text { alate } \\
\text { synthase }\end{array}$ & $\begin{array}{l}\text { pep:novel } \\
\text { supercontig:GCA_000504845.1:contig000411:16560 } \\
\text { :18359:-1 gene:O978_19245 transcript:ETB00930 } \\
\text { description:"'2-isopropylmalate synthase"'" }\end{array}$ & 0,75 \\
\hline
\end{tabular}




\begin{tabular}{|c|c|c|c|c|}
\hline 9 & AAS06690 & RpsL & $\begin{array}{l}\text { pep:novel } \\
\text { chromosome:GCA_000007865.1:Chromosome:461 } \\
\text { 7754:4618128:1 gene:MAP_4140 } \\
\text { transcript:AAS06690 description:"'RpsL'"' }\end{array}$ & 0,67 \\
\hline 10 & $\begin{array}{l}\text { AAS06681; } \\
\text { ETB45918; } \\
\text { ETB45924 }\end{array}$ & RpoC & $\begin{array}{l}\text { pep:novel } \\
\text { chromosome:GCA_000007865.1:Chromosome:460 } \\
\text { 6729:4610679:1 gene:MAP_4131 } \\
\text { transcript:AAS06681 description:"'"RpoC'"' }\end{array}$ & 0,62 \\
\hline 11 & AAS06680 & RpoB & $\begin{array}{l}\text { pep:novel } \\
\text { chromosome:GCA_000007865.1:Chromosome:460 } \\
\text { 3087:4606683:1 gene:MAP_4130 } \\
\text { transcript:AAS06680 description:"'"RpoB"'" }\end{array}$ & 0,48 \\
\hline 12 & AAS02778 & ClpC & $\begin{array}{l}\text { pep:novel } \\
\text { chromosome:GCA_000007865.1:Chromosome:488 } \\
\text { 298:490829:1 gene:MAP_0461 transcript:AAS02778 } \\
\text { description:"'ClpC'"' }\end{array}$ & 0,46 \\
\hline 13 & ETB04840 & $\begin{array}{l}\text { GTP- } \\
\text { binding } \\
\text { protein } \\
\text { YchF }\end{array}$ & $\begin{array}{l}\text { pep:novel } \\
\text { supercontig:GCA_000504785.1:contig000104:1736: } \\
\text { 2809:1 gene:O979_06015 transcript:ETB04840 } \\
\text { description:"'GTP-binding protein YchF"'" }\end{array}$ & 0,43 \\
\hline 14 & $\begin{array}{l}\text { ЕTВ04389 } \\
\text { AAS04768 }\end{array}$ & $\begin{array}{l}\text { ATP } \\
\text { synthase } \\
\text { subunit } \\
\text { beta }\end{array}$ & $\begin{array}{l}\text { pep:novel } \\
\text { supercontig:GCA_000504785.1:contig000131:12100 } \\
: 13557: 1 \quad \text { gene:O979_07275 transcript:ETB04389 } \\
\text { description:"'ATP synthase subunit beta"'" }\end{array}$ & 0,26 \\
\hline 15 & AAS06390 & DnaK & $\begin{array}{l}\text { pep:novel } \\
\text { chromosome:GCA_000007865.1:Chromosome:429 } \\
\text { 5544:4297415:1 gene:MAP_3840 } \\
\text { transcript:AAS06390 description:"'DnaK"'" }\end{array}$ & 0,04 \\
\hline
\end{tabular}




\section{Figure 1}

Overlap (Venn diagram) of differentially ( $\geq 5$ fold) expressed proteins between secretomes/exoproteomes of control cow (blue) and ID cow (red). From a total of 811 identified proteins, 90 were higher abundant in control and 38 in ID.

Overlap (Venn diagram) of differentially ( $\geq 5$ fold) expressed proteins between secretomes/exoproteomes of control cow (blue) and ID cow (red). From a total of 811 identified proteins, 90 were higher abundant in control and 38 in ID.

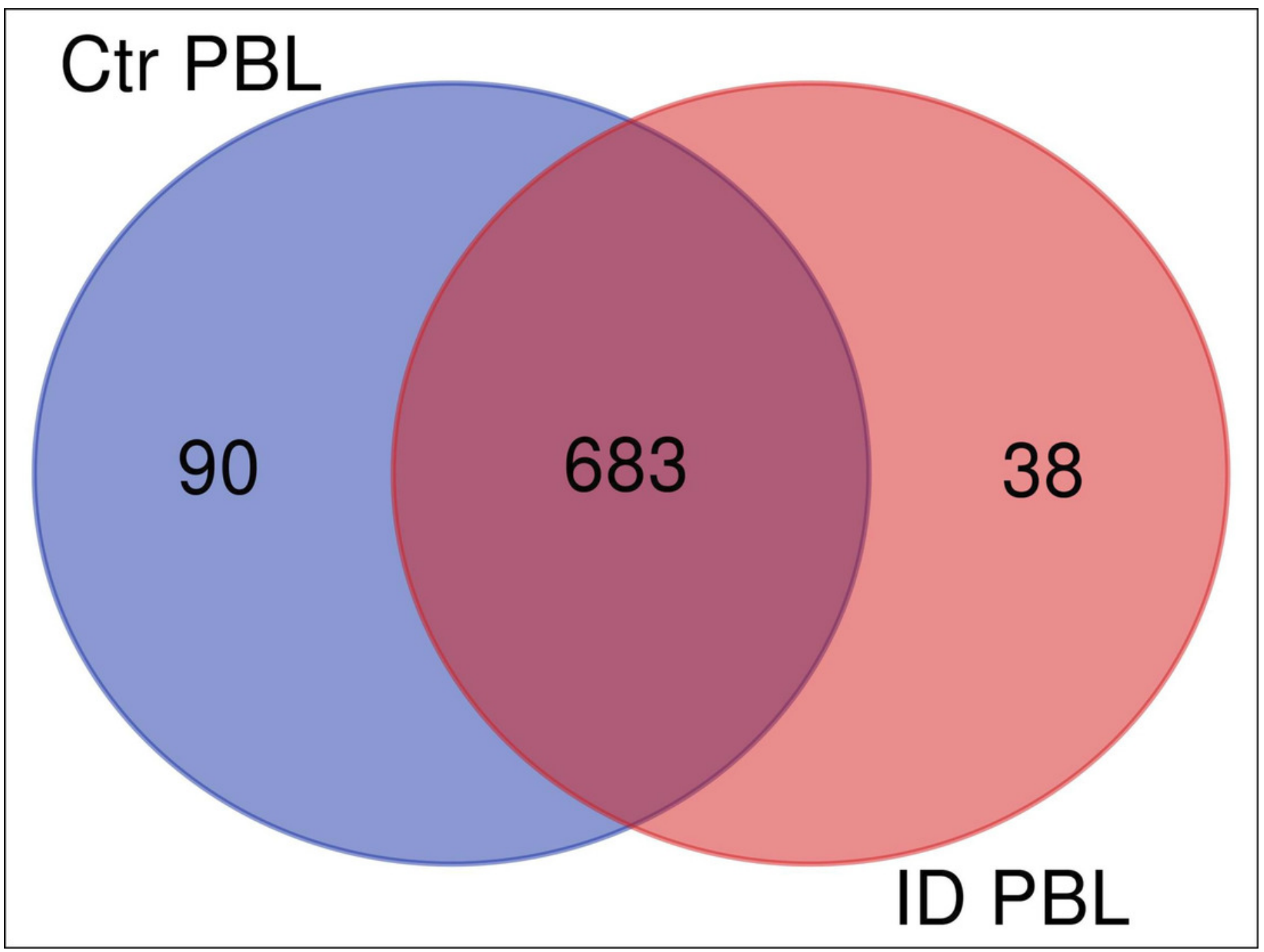




\section{Figure 2}

Hierarchical clustering tree and network of related GO terms of differentially expressed proteins in secretomes/exoproteomes of control PBL (A) and ID PBL (B) illustrates marked differences. GO terms are grouped together based on how many genes they share

Hierarchical clustering tree and network of related GO terms of differentially expressed proteins in secretomes/exoproteomes of control PBL (A) and ID PBL (B) illustrates marked differences. GO terms are grouped together based on how many genes they share. The size of the solid circle corresponds to the enrichment false discovery rate.

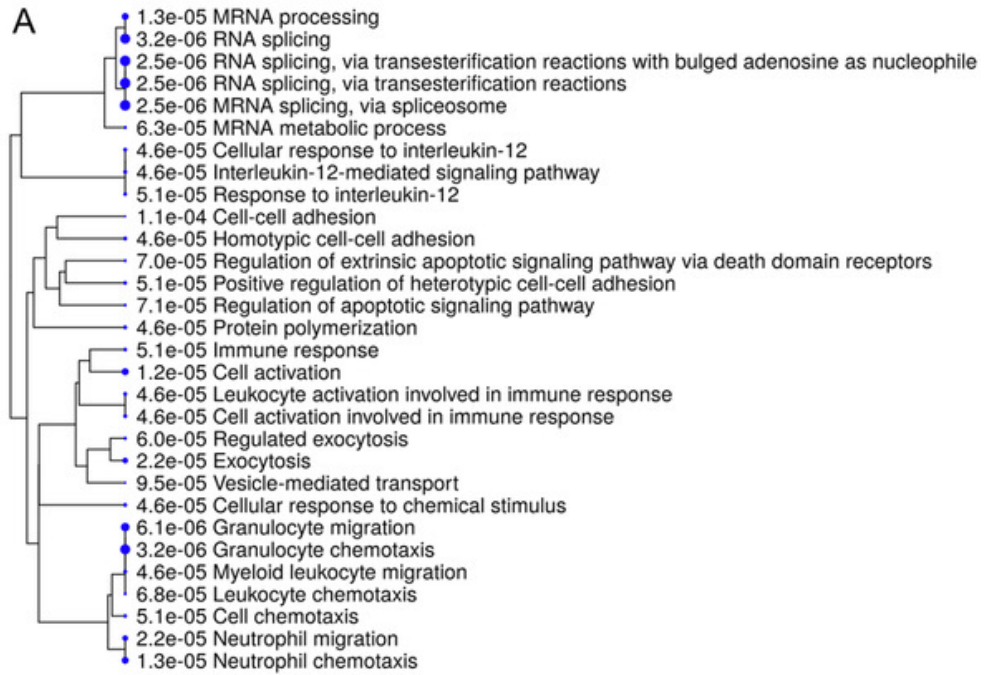

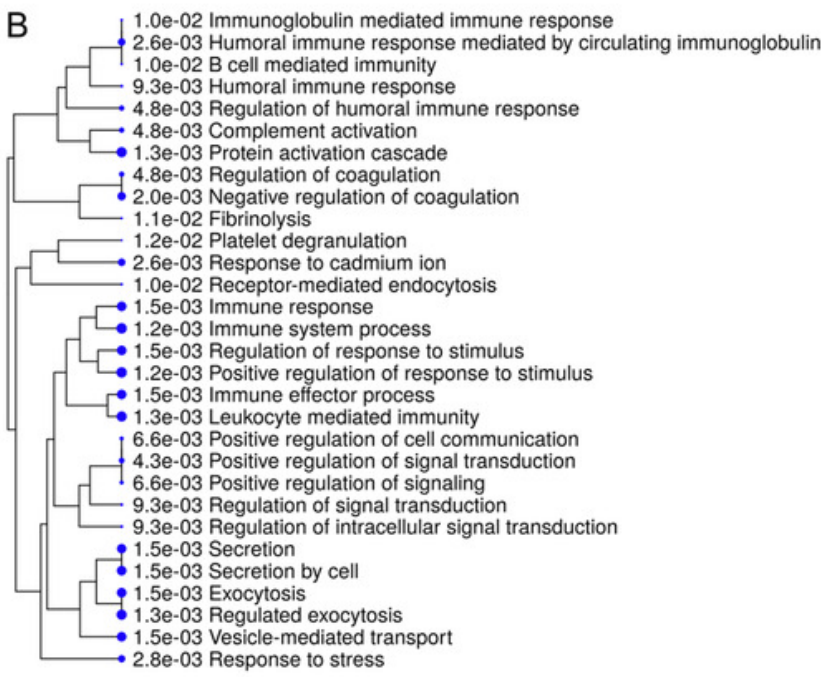




\section{Figure 3}

Visualization of overlapping relationships among enriched gene-sets revealed A) two major networks as shown by network view for enriched GO molecular component terms in control PBL after MAP infection and B) in ID PBL after MAP infection. Related GO terms

Visualization of overlapping relationships among enriched gene-sets revealed A) two major networks as shown by network view for enriched GO molecular component terms in control PBL after co-incubation with MAP and B) in ID PBL after co-incubation with MAP. Related GO terms are connected by a line whose thickness reflects percent of overlapping genes. Size of the nodes corresponds to number of genes.

A
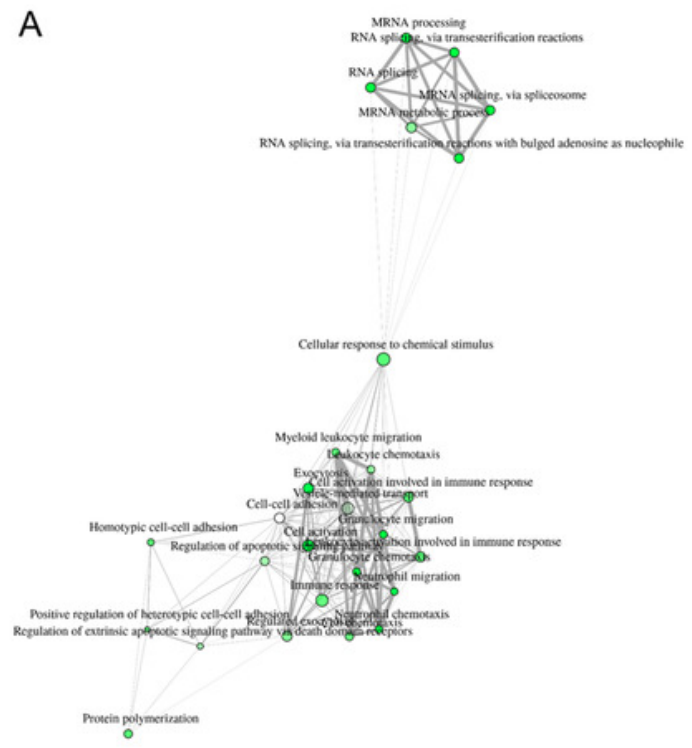

B

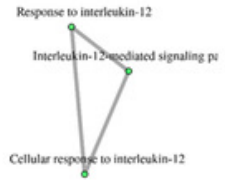

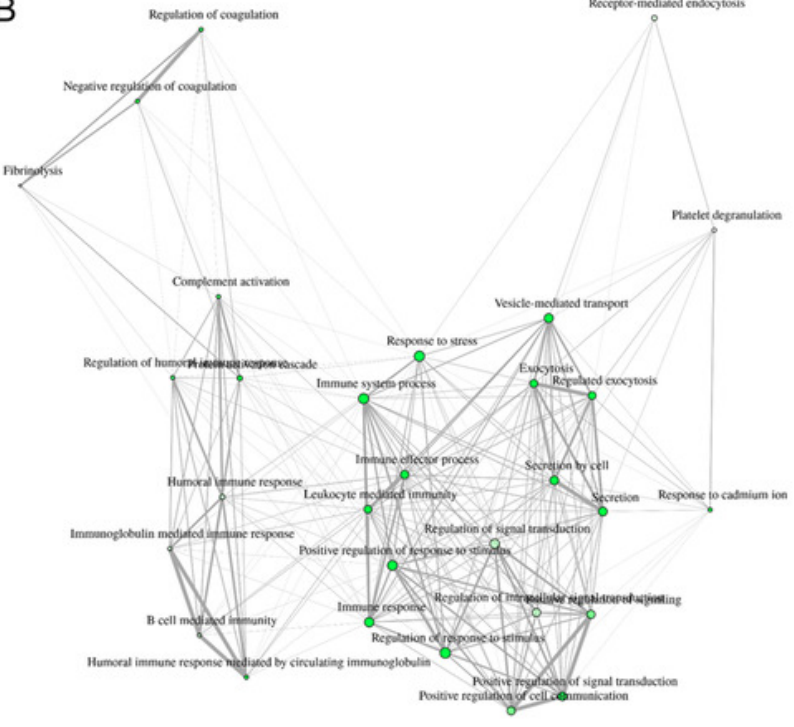

